\title{
KLASIFIKASI BERITA OLAHRAGA MENGGUNAKAN METODE NAÏVE BAYES DENGAN ENHANCED CONFIX STRIPPING STEMMER
}

\author{
Yoga Dwitya Pramudita ${ }^{1}$, Sigit Susanto Putro ${ }^{2}$, Nurul Makhmud ${ }^{3}$ \\ ${ }^{123}$ Prodi Teknik Informatika Universitas trunojoyo \\ Email: ${ }^{1}$ yoga@ $@$ trunojoyo.ac.id, ${ }^{2}$ sigit.putro@trunojoyo.ac.id
}

(Naskah masuk: 6 Mei 2018, diterima untuk diterbitkan: 7 Agustus 2018)

\begin{abstract}
Abstrak
Dokumen berita olahraga dalam bentuk web kini memiliki jumlah yang besar dalam kurun waktu singkat. Untuk kemudahan akses dokumen perlu melakukan pengelompokan dokumen berita kedalam beberapa kategori. Hal tersebut bertujuan agar berita olahraga tersusun sesuai dengan kategori yang ditentukan. Berita dapat dikelompokkan secara manual oleh manusia, akan tetapi hal tersebut membutuhkan waktu yang lama untuk melakukan kategorisasi. Metode klasifikasi diusulkan dalam penelitian ini untuk melakukan pengkategorian secara otomatis dokumen berita. Tujuan dilakukannya klasifikasi adalah untuk mempercepat dan mempermudah dalam pemberian kategori, sehingga dapat meningkatkan efisiensi waktu. Pada penelitian ini menggunakan metode klasifikasi Naïve Bayes Classifier. Sebelum dilakukan klasifikasi ada proses preprocessing dengan menggunakan Enhanced Confix Striping Stemmer. Hal ini bertujuan untuk mengembalikan ke bentuk kata dasar, sehingga data berkurang dan proses komputasi menjadi lebih efisien. Pengujian dilakukan menggunakan 18 berita olahraga yang dipilih secara acak oleh user atau tester, dari 18 berita yang diujikan terdapat 14 berita yang bernilai benar atau relevan dengan analisis yang dilakukan use atau tester pada berita uji. Dari penelitian ini dapat disimpulkan bahwa Aplikasi Klasifikasi Berita Olahraga menggunakan Metode Naïve Bayes dengan Enhanced Confix Striping Stemmer mampu mengklasifikasi berita olahraga sesuai dengan kategori masing-masing, seperti Sepak Bola, Basket, Raket, Formula 1, Moto GP dan olahraga lainnya dengan keakuratan sebesar 77\%.
\end{abstract}

Kata kunci: Klasifikasi, Berita Olahraga, Nä̈ve Bayes Classifier, Enhance Confix Stripping Stemmer

\section{SPORTS NEWS CLASSIFICATION USING NAÏVE BAYES WITH ENHANCED CONFIX STRIPPING STEMMER}

\begin{abstract}
Web-based sports news currently has a considerable amount of documents. News documents need to be grouped into multiple categories for easy access. The goal is that sports news is structured according to the specified category. News can be grouped manually by humans, but it takes a long time to categorize if it involves large documents. Classification method is proposed in this research to categorize automatically news document. The purpose of doing the classification is to accelerate and simplify the granting of categories, thereby increasing the efficiency of time. In this research using the Nä̈ve Bayes Classifier classification method. Prior to classification there is a preprocessing process using Enhanced Confix Striping Stemmer. It aims to return to the basic word form, so the data is reduced and the computing process becomes more efficient. From the test using 18 sports news randomly selected by the user or tester, there are 14 news stories that are true or relevant to the analysis by the user or the tester on the test news. This study concludes that the Sports News Classification Application using the Naïve Bayes Method with Enhanced Confix Striping Stemmer is able to classify sports news according to their respective categories, such as Football, Basket, Racquet, Formula 1, Moto GP and other sports with accuracy of $77 \%$.
\end{abstract}

Keywords: Classification, Sports News, Nä̈ve Bayes Classifier, Enhance Confix Stripping Stemmer

\section{PENDAHULUAN}

Berita adalah informasi berdasarkan fakta atau laporan mengenai suatu kejadian yang sedang atau telah terjadi dan dipublikasikan melalui media cetak, siaran, internet maupun dari mulut ke mulut. Dengan adanya berita, masyarakat menjadi lebih tahu mengenai kejadian terkini. Berita olahraga merupakan salah satu berita yang paling banyak diakses oleh masyarakat. Pada alexa.com situs berita olahraga seperti sport.detik.com, bola.net masuk pada 
25 top site di Indonesia. Hal tersebut menunjukkan bahwa masyarakat lebih memilih mengakses berita olahraga melalui internet. Berbeda dengan media cetak ataupun siaran, berita melalui internet dapat kapan saja diakses tanpa adanya batas waktu. Akan tetapi seiring dengan berjalannya waktu, jumlah berita olahraga pada internet akan semakin besar. Besarnya jumlah berita membuat berita tersebut perlu diorganisasi kedalam kelompok atau kategorisasi sesuai dengan isi dari berita. Dengan tujuan agar berita tersebut terorganisir sehingga memudahkan dalam hal akses. Kategorisasi dapat dilakukan dengan menerapkan teknik data mining yaitu klasifikasi.

Data mining adalah suatu proses ekstraksi atau penggalian dari data yang belum diketahui sebelumnya (Thomas, 2015). Data tersebut digali dari database besar dan digunakan untuk membuat suatu keputusan bisnis yang sangat penting. Sedangkan klasifikasi adalah pengolahan untuk menemukan kumpulan model (atau fungsi) yang menggambarkan dan membedakan kelas data atau konsep, dengan tujuan mampu menggunakan model untuk memprediksi kelas dari objek yang label kelasnya tidak diketahui. Model didasarkan pada analisis kumpulan data latih (jiawei, 2000).

Sebelum berita dapat diklasifikasi, perlu melakukan tahap preprocessing. Preprocessing itu sendiri terdiri dari beberapa tahapan, yaitu : case folding, tokenizing/parsing, filtering dan stemming (Triawati, 2009). Pada tahapan preprocessing, proses stemming merupakan proses yang terpenting karena pada stemming terjadi penghilangan kata imbuhan sehingga menghasilkan kata dasar. Algoritma yang digunakan pada proses stemming adalah Algoritma Enhanced Confix Stripping Stemmer. Algoritma tersebut merupakan pengembangan dari Algoritma Confix Stripping dengan melakukan beberapa perbaikan aturan sehingga memiliki tingkat kesalahan paling sedikit dibandingkan algoritma sebelumnya (Putu, 2008).

Klasifikasi yang digunakan adalah Nä̈ve Bayes Classifier. Klasifikasi ini adalah model probalistik yang simpel untuk klasifikasi data kedalam kelas yang spesifik berdasarkan fitur data yang berbeda (Friedman, 1997). Nä̈ve Bayes telah menjadi metode utama yang digunakan pada klasifikasi untuk variasi pada data mulai dari medis, jaringan komputer dan teks karena kesederhanaan, keefektifan, dan kapabilitas menangkap penalaran data dalam model grafis (Abraham, 2009; Zgan \& Gao, 2011; Mukherjee \& Sharmaa, 2012). Kelebihan Nä̈ve Bayes Classifier yaitu konsep yang mudah dimengerti, tidak sensitif terhadap fitur yang relevan, dapat menangani data real maupun diskrit (Eamonn). Meskipun asumsi bahwa fitur-fitur dataset bersifat independent adalah sebuah asumsi yang kurang baik tetapi kenyataannya hasil klasifikasi berbasis Nä̈ve Bayes memiliki kinerja yang mampu berkompetisi dengan metode-metode lain yang lebih kompleks dalam aspek komputasinya (Bagus, 2016). Nä̈ve
Bayes Classifier memiliki keunggulan dalam hal waktu komputasi dibandingkan dengan algoritma klasifikasi lainnya (Dwi, 2012).

Penelitian tentang klasifikasi berita sudah pernah dilakukan sebelumnya, diantaranya yaitu penelitian menggunakan metode Naïve Bayes dengan fitur $N$-Gram untuk mengklasifikasi berita lokal radar Malang. Dokumen latih diambil dari web portal www.kompas.com dimana terdapat beberapa kategori dengan dokumen politik, ekonomi, news, edukasi, kesehatan, travel, dan olahraga. Sedangkan dokumen uji diambil pada portal www.radarmalang.co.id. Pada penelitian ini dilakukan 5 ujicoba. Pada kelima ujicoba yang dilakukan didapatkan ketepatan prediksi atau akurasi sebesar 78.66\%, 68.20\%, 59.24\%, 65.93\%, 74.39\% (Denny, 2016).

Penelitian selanjutnya menggunakan metode Nä̈ve Bayes dengan Natural Langage Processing untuk mengklasifikasi jenis berita pada arsip pemberitaan. Pada penelitian ini, awalnya setiap artikel akan dijabarkan kata per kata dan dipisah atau dibersihkan dari penggunaan tanda baca, kalimat positif dan negatif dengan metoda natural language processing. Kemudian setiap paragraf akan diambil kata kunci. Kata kunci akan di input sebagai data latih ke dalam Database. Setelah pemecahan kata, langkah selanjutnya adalah setiap data akan diklasifikasikan dengan metode Nä̈ve Bayes. Dari percobaan yang dilakukan dengan 4 kategori artikel masing-masing memberikan nilai akurasi hingga lebih dari $82 \%$, dimana pada percobaan 1 didapatkan akurasi sebesar $82.5 \%$, pada percobaan 2 didapatkan akurasi sebesar $89 \%$, pada percobaan 3 didapatkan akurasi sebesar $89.375 \%$, pada percobaan 4 didapatkan akurasi sebesar $90 \%$, dan pada percobaan didapatkan 5 akurasi sebesar 94.16667\% (Novia, 2016).

Penelitian berikutnya menggunakan metode Nä̈ve Bayesian Classification dan Support Vector Machine dengan Confix Stripping Stemmer untuk mengklasifikasi berita Indonesia. Dalam penelitian ini data telah dibagi menjadi dua yaitu data latih dan uji dengan proporsi 70:30. Jumlah word vector yang akan diuji coba pada data latih adalah 1000, 1500, 2000, 2500, 3000, 3500, 4000, 4500, dan 10000. Sedangkan untuk data uji karena jumlah artikel berita lebih sedikit maka word vector yang akan digunakan adalah 1000, 1500, 2000, 2500, dan 3000. Pada penelitian ini dihasilkan bahwa semakin banyak jumlah word vector pada data latih maka semakin tepat hasil akurasi yang dihasilkan yaitu dengan akurasi sebesar 82,22\% untuk klasifikasi menggunakan metode Nä̈ve Bayes Classifier. Sedangkan klasifikasi dengan menggunakan metode Support Vector Machine, hasil ketepatan klasifikasi pada data latih dipengaruhi oleh parameter $\mathrm{C}$ dan Gamma. Semakin mengecil nilai gamma semakin mengurangi ketepatan klasifikasi sehingga perlu ditambahkan parameter $\mathrm{C}$ yang lebih besar. Nilai parameter $\mathrm{C}$ yang digunakan 10-2 hingga 104. Hasil 
akurasi yang dihasilkan pada data uji menggunakan kernel linear yaitu sebesar 88,1\% (Dio, 2015).

Implementasi Algoritma Nä̈ve Bayes Classifier Berbasis Particle Swarm Optimization (PSO) Untuk Klasifikasi Konten Berita Digital Bahasa Indonesia. Pada penelitian ini, peneliti melakukan pengujian model dengan menggunakan teknik 10 cross validation, di mana proses tersebut membagi data secara acak ke dalam 10 bagian. Proses pengujian dimulai dengan pembentukan model dengan data pada bagian pertama. Model yang terbentuk akan diujikan pada 9 bagian data sisanya. Setelah itu proses akurasi dihitung dengan melihat seberapa banyak data yang sudah terklasifikasi dengan benar. Dari hasil pengujian yang dilakukan membuktikan bahwa algoritma Nä̈ve Bayes Classifier berbasis Particle Swarm Optimization memiliki nilai akurasi sebesar $94.17 \%$ yang didapat saat proses ke-5 fold cross validation (Nurhadi, 2016).

Implementasi dari Metode K-Nearest Neighbor dengan Decision Rule dilakukan untuk Klasifikasi Subtopik Berita. Pada penelitian ini dilakukan 3 kali percobaan dengan nilai $\mathrm{k}$ yang berbeda yaitu $\mathrm{k}=3, \mathrm{k}=5, \mathrm{k}=7$, didapatkan hasil akurasi $88,29 \%$ untuk $\mathrm{k}=3,88,29 \%$ untuk $\mathrm{k}=5$, dan $87,23 \%$ untuk $\mathrm{k}=7$, dari percobaan yang dilakukan disimpulkan bahwa nilai k tidak banyak berpengaruh pada hasil akhir $K$-Nearest karena persentase keakuratan rata-rata masih diatas $80 \%$ (tergolong baik). Sedangkan keakuratan klasifikasi dengan menggunakan $K$-Nearest dengan Decision Rule, dengan nilai $\mathrm{k}$ yang sama yaitu $\mathrm{k}=3, \mathrm{k}=5, \mathrm{k}=7$ didapatkan hasil yang tidak jauh berbeda dengan klasifikasi menggunakan $K$-Nearest yaitu dengan akurasi sebesar $89,36 \%$ untuk $\mathrm{k}=3,86,17 \%$ untuk $\mathrm{k}=5,87,23 \%$ untuk $\mathrm{k}=7$. Hanya terjadi peningkatan akurasi sebesar $2 \%$ pada $\mathrm{k}=3$. Jadi dapat disimpulkan penggunaan $\mathrm{k}=3$ merupakan hasil klasifikasi yang menunjukkan presentase terbaik dalam $K$-Nearest Neighbor maupun $K$-Nearest Neighbor with Decision Rule (Yoseph dkk, 2015).

Dari paparan diatas, pada penelitian ini melakukan klasifikasi berita olahraga menggunakan metode Nä̈ve Bayes dengan Enhanced Confix Stripping Stemmer sebagai algoritma stemming. Tujuannya adalah mengetahui seberapa akurat klasifikasi yang dihasilkan jika menggunakan preprocessing tersebut.

\section{METODE}

Klasifikasi adalah proses pencarian sekumpulan model atau fungsi yang menggambarkan dan membedakan kelas data dengan tujuan agar model tersebut dapat digunakan untuk memprediksi kelas dari suatu objek yang belum diketahui kelasnya. Klasifikasi memiliki dua proses yaitu membangun model klasifikasi dari sekumpulan kelas data yang sudah didefinisikan sebelumnya (training data set) dan menggunakan model tersebut untuk klasifikasi data tes serta mengukur akurasi dari model (Rachli, 2007).

\subsection{TEXT PREPROCESSING}

Text Preprocessing adalah suatu proses pengubahan bentuk data yang belum terstruktur atau tidak terstruktur menjadi data yang terstruktur (mengubah teks menjadi term index). Tujuannya adalah untuk memperkecil dimensi data sehingga proses komputasi lebih menjadi efisien dan diharapkan lebih presisi. Preprocessing terdiri dari beberapa tahapan. Adapun tahapan preprocessing berdasarkan, yaitu : case folding, tokenizing/ parsing, filtering dan stemming (Triawati, 2009).

1. Case Folding adalah mengubah semua huruf dalam teks menjadi huruf kecil.

2. Tokenizing adalah sebuah proses untuk memilah isi teks sehingga menjadi satuan kata-kata.

3. Filtering adalah tahap mengambil kata-kata penting dari hasil token. Bisa menggunakan algoritma stoplist (membuang kata yang kurang penting) atau wordlist (menyimpan kata penting).

4. Stemming adalah suatu proses untuk mereduksi kata ke bentuk dasarnya. Tahap stemming merupakan tahap mencari akar (root) kata dari tiap kata hasil filtering (Agus dkk, 2015).

\subsection{ALGORITMA ENHANCED CONFIX STRIPPING STEMMER}

Algoritma Enhanced Confix Stripping Stemmer merupakan perbaikan dari algoritma sebelumnya yaitu, algoritma Confix Stripping Stemmer. Setelah dilakukan beberapa percobaan dan analisis, ditemukan beberapa kata yang tidak dapat di-stemming menggunakan Confix Stripping Stemmer yaitu sebagai berikut (Andita dkk, 2010) :

1. Kurangnya aturan pemenggalan awalan untuk kata-kata dengan format "mem+p...", Contohnya yaitu terjadi pada kata "mempromosikan", "memproteksi"

2. Kurangnya aturan pemenggalan awalan untuk kata-kata dengan format "men+s...", Contohnya yaitu terjadi pada kata "mensyaratkan", "mensyukuri".

3. Kurangnya aturan pemenggalan awalan untuk kata-kata dengan format "menge+...". Contohnya yaitu terjadi pada kata "mengerem".

4. Kurangnya aturan pemenggalan awalan untuk kata-kata dengan format "penge+...". Contohnya yaitu terjadi pada kata "pengeboman".

5. Kurangnya aturan pemenggalan awalan untuk kata-kata dengan format "peng+k...". Contohnya yaitu terjadi pada kata "pengkajian". 
6. Adanya elemen pada beberapa kata dasar yang menyerupai suatu imbuhan. Kata-kata seperti "pelanggan", "perpolitikan", dan "pelaku" gagal distemming karena akhiran "-an", "-kan" dan “-ku” seharusnya tidak dihilangkan.

Pada Algoritma Enhanced Confix Stripping Stemmer terdapat beberapa modifikasi aturan pemenggalan yang yang dapat dilihat pada tabel 1 .

Tabel 1. Modifikasi dan Tambahan Aturan Oleh Enhanced Confix Stripping Stemmer

\begin{tabular}{|c|c|c|}
\hline Aturan & Format Kata & Pemenggalan \\
\hline 14 & $\operatorname{men}\{\mathrm{e}|\mathrm{c}| \mathrm{d}|\mathrm{j}| \mathrm{z}\} \ldots$ & men- $\{\mathrm{e}|\mathrm{c}| \mathrm{d}|\mathrm{j}| \mathrm{z}\} \ldots$ \\
\hline 17 & mengV... & $\begin{array}{l}\text { meng-V... } \mid \text { meng- } \\
\mathrm{kV} \ldots \mid \text { (meng } \mathrm{V}-\ldots \\
\text { Jika } \mathrm{V}=\mathrm{e}^{\prime} \text { ') }\end{array}$ \\
\hline 19 & mempA... & $\begin{array}{l}\text { mem-pA...dimana } \\
\text { A! ='e' }\end{array}$ \\
\hline 28 & pengC... & peng-C... \\
\hline 29 & pengV... & $\begin{array}{l}\text { peng-V... | peng- } \\
\mathrm{kV} . . . \mid \text { (pengV-... } \\
\text { Jika V='e') }\end{array}$ \\
\hline
\end{tabular}

Untuk memperbaiki kesalahan yang telah disebutkan diatas, algoritma Enhanced Confix Stripping Stemmer melakukan beberapa perbaikan sebagai berikut (Andita dkk, 2010):

1. Melakukan modifikasi beberapa aturan.

2. Menambahkan suatu algoritma tambahan untuk mengatasi kesalahan pemenggalan akhiran. Algoritma tambahan kemudian disebut dengan loopPengembalianAkhiran. Langkah ini dilakukan apabila proses recoding gagal.

Algoritma loopPengembalianAkhiran didefinisikan sebagai berikut :

1. Mengembalikan seluruh awalan yang telah dihilangkan sebelumnya, sehingga menghasilkan model kata seperti berikut : $[\mathrm{DP}+[\mathrm{DP}+[\mathrm{DP}]]]+$ Kata Dasar.

Pemenggalan awalan dilanjutkan dengan proses pencarian di kamus, kemudian dilakukan pada kata yang telah dikembalikan menjadi model tersebut. Jika proses tersebut sukses maka akan dihentikan, apabila tidak sukses maka langkah selanjutnya akan dilakukan.

2. Mengembalian akhiran yang telah dihilangkan sebelumnya. Hal ini artinya bahwa pengembalian dimulai dari DS (“-i”, "-kan", "-an"), lalu PP ("-ku”, "-mu”, "nya”), dan terakhir adalah P (“-lah”, “-kah”, “-tah”, “-pun”). Untuk setiap pengembalian, lakukan langkah 3) hingga 5) berikut. Khusus untuk akhiran "-kan", pengembalian pertama dimulai dengan " $k$ ", baru kemudian dilanjutkan dengan "an".

3. Lakukan pengecekan di kamus kata dasar. Apabila ditemukan, proses dihentikan. Apabila gagal, maka lakukan proses pemenggalan awalan berdasarkan aturan.

4. Lakukan recoding apabila diperlukan.

Apabila pengecekan di kamus kata dasar tetap gagal setelah recoding, maka awalan-awalan yang telah dihilangkan dikembalikan lagi.

\subsection{TERM FREQUENCY}

Term Frequency merupakan salah satu metode untuk menghitung bobot tiap term dalam text. Pada metode ini, tiap term diasumsikan memiliki nilai kepentingan yang sebanding dengan jumlah kemunculan term tersebut pada text (Diah, 2010).

\subsection{NAÏVE BAYES CLASSIFIER}

Nä̈ve Bayes Clasifier atau disebut juga dengan Bayesian Classification merupakan metode pengklasifikasian statistik yang didasarkan pada teorema bayes yang dapat digunakan untuk memprediksi probabilitas keanggotaan suatu kelas (Muhammad, 2017).

Nä̈ve Bayes Classifier pada penelitian ini digunakan untuk mengklasifikasikan dokumen teks. Pada algoritma Nä̈ve Bayes setiap dokumen dipresentasikan dengan masukan atribut " $\mathrm{a}_{1}, \mathrm{a}_{2}$, $\mathrm{a}_{3}, \ldots, \mathrm{a}_{\mathrm{n}}$ " dimana $\mathrm{a}_{1}$ adalah kata pertama dan berikutnya sampai $a_{n}(k a t a k e-n)$, sedangkan $V$ yaitu label kategori. Selanjutnya yaitu mencari nilai tertinggi dari kategori teks yang diujikan ( $\mathrm{V}_{\mathrm{MAP}}$ ) (McCallum, 1998). Persamaan $\mathrm{V}_{\text {MAP }}$ yaitu sebagai berikut (Bagus, 2016) :

$\mathrm{V}_{\mathrm{MAP}}=\underset{\mathrm{vj} \in \mathrm{V}}{\operatorname{argmax}} \mathrm{P}\left(\mathrm{v}_{\mathrm{j}}\right) \prod_{\mathrm{i}} \mathrm{P}\left(\mathrm{a}_{\mathrm{i}} \mid \mathrm{v}_{\mathrm{j}}\right)$

Nilai $P\left(v_{j}\right)$ dihitung pada saat data latih, dengan rumus sebagai berikut :

$\mathrm{P}\left(\mathrm{v}_{\mathrm{j}}\right)=\frac{\mid \text { dokumen } \mathrm{j} \mid}{\mid \text { dok. } \text { training } \mid}$

Dimana :

|dokumen j| adalah jumlah dokumen yang memiliki kategori j pada dokumen latih.

|dok. training| adalah jumlah dokumen latih.

$\mathrm{P}\left(a_{i} \mid v_{j}\right)=\frac{\left|n_{i}+1\right|}{\mid n+\text { kosa kata } \mid}$

Dimana :

1. $n_{i}$ adalah jumlah kemunculan kata $a_{i}$ pada dokumen yang berkategori $\mathrm{v}_{\mathrm{j}}$

2. n adalah jumlah seluruh kata pada dokumen yang berkategori $\mathrm{v}_{\mathrm{j}}$ 
3. kosakata adalah jumlah kata pada seluruh dokumen latih.

Untuk mengetahui tingkat akurasi dari luaran klasifikasi maka bisa dihitung dengan menggunakan rumus akurasi berikut.

Perhitungan Akurasi :

Akurasi $=\frac{\text { Jumlah Dokumen Diuji Benar }}{\text { Jumlah Dokumen diujikan }} \chi 100 \%$

\section{ARSITEKTUR SISTEM}

Pada gambar 1 menunjukkan arsitektur klasifikasi dokumen berita olahraga. Terdapat dua pembagian dokumen, yaitu dokumen latih dan dokumen uji. Pada dokumen latih dilakukan proses pembelajaran (learning) pada setiap kategori untuk menghasilkan model probabilitas.

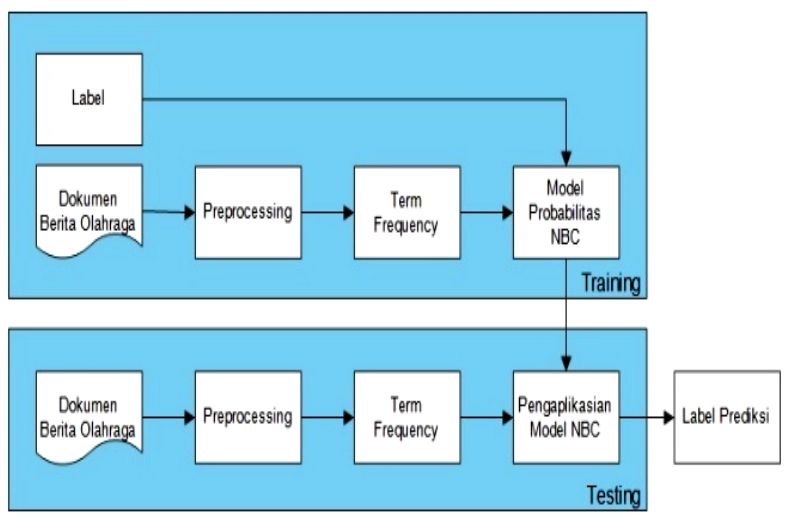

Gambar 1. Gambaran umum sistem

Sebelum dilakukan proses pembelajaran (learning), dokumen terlebih dahulu melalui tahap preprocessing dan perhitungan term frequency. Sama halnya dengan dokumen latih, dokumen uji juga melalui tahap preprocessing dan perhitungan term frequency setelah selanjutnya dilakukan proses pengklasifikasian yang mengacu pada model probabilitas yang dihasilkan pada proses pembelajaran (learning), dan label kategori pada dokumen uji dapat ditentukan dengan mencari nilai $\mathrm{V}$ (nilai tertinggi dari kategori teks yang diujikan.

Arsitektur dari sistem yang akan dibuat, akan dideskripsikan pada beberapa flowchart pada gambar 2. Flowchart tersebut menunjukan alur dari proses pengklasifikasian dengan metode Nä̈ve Bayes. Adapun tahapannya yaitu input-kan dokumen uji berita olahraga. Lalu dokumen tersebut dilakukan preprocessing. Setelah dokumen dilakukan preprocessing, selanjutnya menghitung term frequency. Langkah selanjutnya yaitu menghitung $\mathrm{V}_{\mathrm{j}}$ $=\mathrm{P}\left(\mathrm{vj}_{\mathrm{j}}\right)$ Пi $\mathrm{P}\left(\mathrm{a}_{\mathrm{i}} \mid \mathrm{v}_{\mathrm{j}}\right)$ untuk setiap kategori dengan mengacu pada model probabilitas yang telah diketahui pada proses pelatihan sebelumnya.
Kategori dapat ditentukan dengan mencari nilai $\mathrm{V}_{\mathrm{j}}$ maksimal.

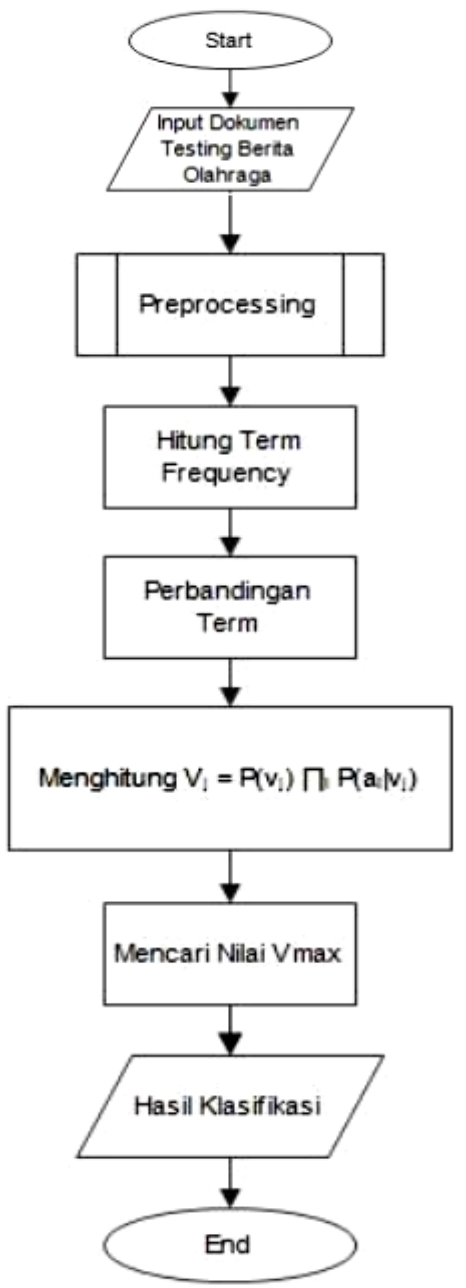

Gambar 2. Flowchart Naïve Bayes Classifier

Pada gambar 3 menunjukan flowchart dari proses preprocessing. Adapun tahapan preprocessing berdasarkan, yaitu : case folding, tokenizing/parsing, filtering dan stemming. Tahapan yang pertama setelah dokumen berita dimasukkankan yaitu tahapan case folding, case folding adalah mengubah huruf kapital (besar) menjadi huruf kecil. Tahap selanjutnya yaitu tahap tokenizing, yaitu proses untuk memilah isi teks sehingga menjadi satuan kata-kata. Setelah melalui tahap tokenizing, selanjutnya yaitu tahap filtering yaitu mengambil kata-kata penting dari hasil token. Pada tahap filtering akan menghilangkan kata stopword atau kata yang dianggap tidak penting. Dan tahapan terakhir pada preprocessing yaitu stemming, stemming adalah mengubah kata ke dalam bentuk aslinya.

Algoritma stemming yang digunakan dalam penelitian ini adalah Algoritma Enhanced Confix Stripping Stemmer. Pada gambar 4 merupakan flowchart Enhanced Confix Stripping Stemmer. Algoritma tersebut merupakan algoritma perbaikan dari algoritma sebelumnya yaitu algoritma Confix Stripping Stemmer. 


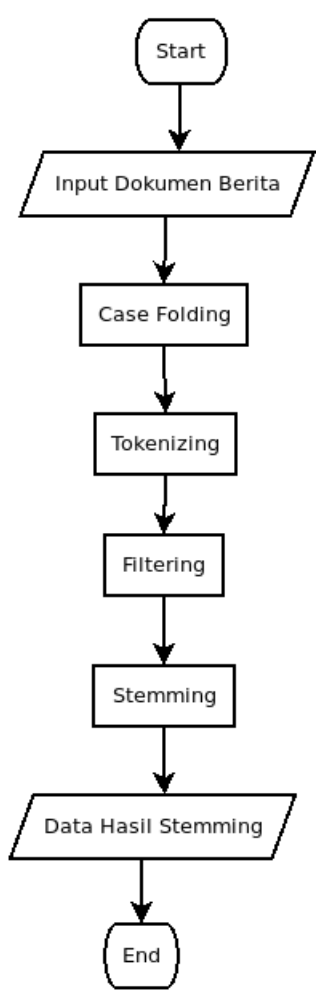

Gambar 3. Flowchart Preprocessing

Langkah pertama pada algoritma stemmer adalah melakukan pengecekan rule Precedence, yaitu kombinasi awalan dan akhiran yang tidak diperbolehkan, kemudian mencocokkan kata yang diinputkan dengan kata dasar pada database. Apabila kata yang dimasukkan dengan kata dasar sama, maka kata tersebut merupakan kata dasar. Jika tidak sama, maka dilanjutkan ke proses hapus akhiran.

Pada hapus akhiran terdapat 3 rule yaitu hapus particle, hapus possesive pronoun, dan hapus derivation suffixes, apabila ketiga rule tersebut telah diproses dan kata yang diproses tadi terdapat kesamaan dengan kata dasar, maka kata tersebut merupakan kata dasar. Jika ketiga rule tersebut telah diproses akan tetapi kata yang diproses tidak terdapat kesamaan dengan kata dasar, maka selanjutnya yaitu jalankan proses hapus awalan.

Pada hapus awalan terdapat proses hapus derivation prefixes, dimana apabila kata yang diproses tadi terdapat kesamaan dengan kata dasar, maka kata tersebut merupakan kata dasar. Apabila telah dilakukan proses hapus awalan akan tetapi kata dasar belum ditemukan, maka proses recoding dilakukan.

Proses recoding merupakan penyusunan kembali kata-kata yang mengalami proses stemming yang berlebih. Pada proses recoding akan dilakukan proses pemenggalan kata. Apabila kata yang mengalami proses recoding sama dengan kata dasar yang ada pada database, maka kata tersebut merupakan kata dasar. Apabila tidak ditemukan kesamaan dengan kata dasar yang ada pada database, maka proses recoding dikatakan gagal, dan akan dilakukan loopPengembalianAkhiran.

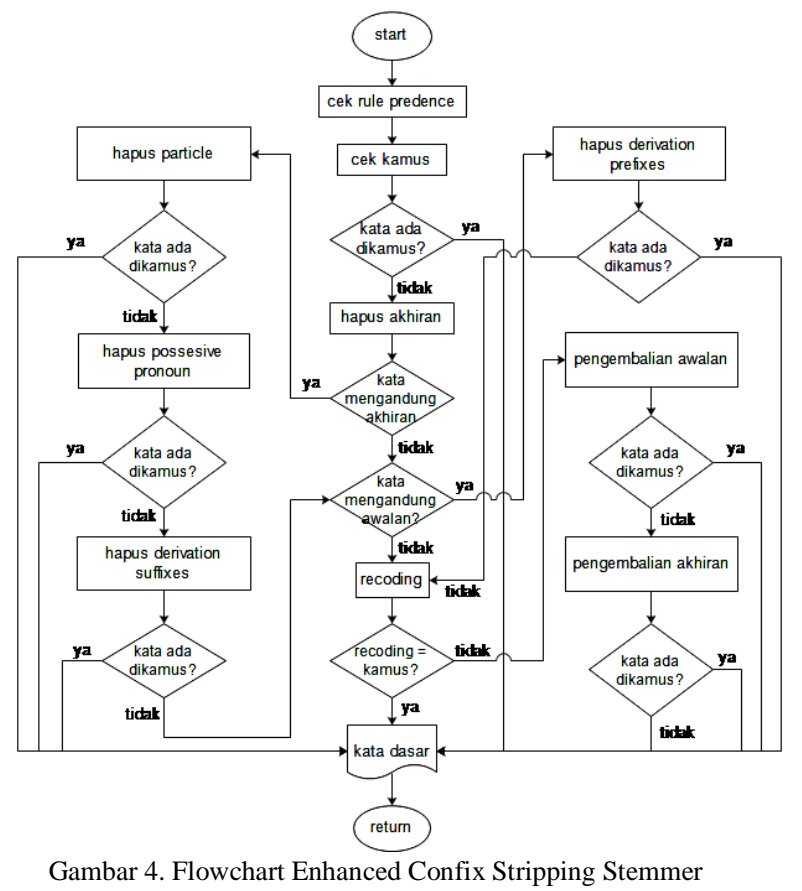

Proses berikutnya adalah mengembalikan seluruh awalan yang telah dihilangkan sebelumnya, sehingga menghasilkan model kata seperti berikut : $[\mathrm{DP}+[\mathrm{DP}+[\mathrm{DP}]]]+$ Kata Dasar. Pemenggalan awalan dilanjutkan dengan proses pencarian di kamus kemudian dilakukan pada kata yang telah dikembalikan menjadi model tersebut. Jika proses tersebut sukses maka akan dihentikan, apabila tidak sukses maka langkah selanjutnya akan dilakukan.

Selanjutnya yaitu mengembalikan akhiran yang telah dihilangkan sebelumnya. Lalu lakukan pengecekan di kamus kata dasar. Apabila ditemukan, proses dihentikan. Apabila tidak ditemukan maka kata tersebut dianggap sebagai kata dasar.

\section{ANALISIS HASIL UJI COBA}

Pada klasifikasi berita olahraga menggunakan metode Nä̈ve Bayes terdapat 2 jenis dokumen berita yaitu berita latih dan berita uji. Berita latih didapat dari situs berita olahraga yaitu sport.detik.com. Peneliti mengambil 151 berita latih dari 6 kategori yaitu sepakbola, basket, raket, motoGP, formula 1 dan berita olahraga lainnya. Berita olahraga lainnya berisi berita olahraga dengan kategori selain dari kelima kategori tersebut, seperti taekwondo, tinju, lari, voli dan lainnya. Pengambilan berita latih dilakukan secara acak oleh peneliti tanpa melakukan seleksi sebelumnya.

Tabel 2. Hasil pengujian

Pengguna : (Wartawan Madura TV) 


\begin{tabular}{|c|c|c|c|c|}
\hline No. & Judul Berita & $\begin{array}{l}\text { Kategori } \\
\text { (Sistem) }\end{array}$ & $\begin{array}{c}\text { Kategori } \\
\text { (User) }\end{array}$ & $\begin{array}{c}\text { Hasil } \\
\text { (Releva } \\
\text { n) }\end{array}$ \\
\hline 1 & $\begin{array}{c}\text { Indonesia Jadi } \\
\text { Runner Up } \\
\text { Kejuaraan Asia } \\
\text { Bulutangkis } \\
\text { Junior } \\
\end{array}$ & Lainnya & Raket & $\mathrm{X}$ \\
\hline 2 & $\begin{array}{c}\text { Chris Froome } \\
\text { Juara Tour de } \\
\text { France untuk } \\
\text { Keempat } \\
\text { Kalinya } \\
\end{array}$ & Lainnya & Lainnya & $\mathrm{V}$ \\
\hline 3 & $\begin{array}{l}\text { FIA Konfirmasi } \\
\text { Halo Akan } \\
\text { Digunakan di F1 } \\
\text { Musim Depan }\end{array}$ & Lainnya & Formula 1 & $\mathrm{X}$ \\
\hline 4 & $\begin{array}{c}\text { Antusiasme } \\
\text { Gerry Salim cs } \\
\text { Hadapi Seri } \\
\text { Balapan ATC di } \\
\text { Sepang } \\
\end{array}$ & Formula 1 & Moto GP & $\mathrm{X}$ \\
\hline 5 & $\begin{array}{c}\text { Jakarta 10K Jadi } \\
\text { Pemanasan } \\
\text { Agus Prayogo } \\
\text { Jelang SEA } \\
\text { Games } \\
\end{array}$ & Lainnya & Lainnya & V \\
\hline 6 & $\begin{array}{c}\text { Jelang } \\
\text { Wimbledon, } \\
\text { Djokovic Rebut } \\
\text { Gelar Juara } \\
\end{array}$ & Raket & Raket & V \\
\hline 7 & $\begin{array}{c}\text { Kala Dhean } \\
\text { Fazrin Tiru } \\
\text { Tendangan } \\
\text { Maut Hwoarang }\end{array}$ & Lainnya & Lainnya & $\mathrm{V}$ \\
\hline 8 & $\begin{array}{c}\text { Maldini: } \\
\text { Bonucci } \\
\text { Pembelian } \\
\text { Bagus untuk } \\
\text { Milan, tapi... }\end{array}$ & Sepakbola & Sepakbola & V \\
\hline 9 & $\begin{array}{c}\text { McGregor } \\
\text { Santai Tanggapi } \\
\text { Prediksi Bakal } \\
\text { Mati Lawan } \\
\text { Mayweather } \\
\end{array}$ & Lainnya & Lainnya & V \\
\hline 10 & $\begin{array}{c}\text { MU Harus } \\
\text { Bahagia Dulu } \\
\text { Sebelum Kejar } \\
\text { Target Musim } \\
\text { Depan } \\
\end{array}$ & Sepakbola & Sepakbola & V \\
\hline 11 & $\begin{array}{c}\text { Pelajaran di } \\
\text { Assen Jadi } \\
\text { Modal Vinales } \\
\text { Hadapi Paruh } \\
\text { Kedua Musim } \\
\end{array}$ & Moto GP & Moto GP & V \\
\hline 12 & $\begin{array}{c}\text { Praveen Debby } \\
\text { Gagal } \\
\text { Persembahkan } \\
\text { Gelar Juara }\end{array}$ & Raket & Raket & $\mathrm{V}$ \\
\hline 13 & $\begin{array}{c}\text { Russell } \\
\text { Westbrook } \\
\text { Sabet Gelar } \\
\text { MVP } \\
\end{array}$ & Basket & Basket & $\mathrm{V}$ \\
\hline 14 & $\begin{array}{c}\text { Terkait Latihan } \\
\text { di Lithuania, } \\
\text { Timnas Basket } \\
\text { Tunggu Surat } \\
\text { Setneg } \\
\end{array}$ & Lainnya & Basket & $\mathrm{X}$ \\
\hline 15 & $\begin{array}{c}\text { Warriors Juara, } \\
\text { Messi dan Barca } \\
\text { Beri Ucapan } \\
\text { Selamat } \\
\end{array}$ & Basket & Basket & $\mathrm{V}$ \\
\hline 16 & $\begin{array}{c}\text { Yamaha Yakin } \\
\text { Vinales Akan } \\
\text { Raih Sejumlah } \\
\text { Titel MotoGP }\end{array}$ & Moto GP & Moto GP & $\mathrm{V}$ \\
\hline 17 & $\begin{array}{c}\text { Tiga Pebalap } \\
\text { ABM } \\
\text { Motorsport Naik } \\
\text { Podium di } \\
\text { ISSOM Seri } \\
\text { Ketiga } \\
\end{array}$ & Formula 1 & Formula 1 & $\mathrm{~V}$ \\
\hline 18 & & Raket & Raket & $\mathrm{V}$ \\
\hline
\end{tabular}

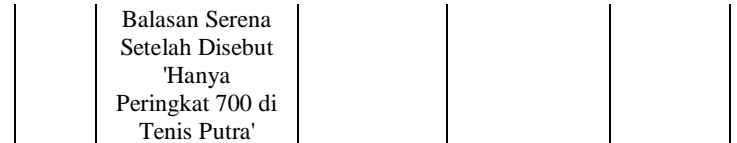

Dari ke-151 berita latih tersebut, akan dilakukan tahap preprocessing, dan perhitungan model probabilitas tiap kata $\mathrm{x}$ terhadap kategori $\mathrm{y}$. Model probabilitas akan menjadi acuan berita uji untuk menemukan label kategori.

Selanjutnya melakukan pengujian terhadap sistem, pengujian dilakukan dengan menggunakan dokumen uji berita olahraga yang diambil dari situs sport.detik.com secara acak dengan jumlah 30 dokumen berita. 30 dokumen berita disimpan dengan file berformat txt. Dari 30 berita uji yang ada, user atau tester hanya memilih 18 berita secara acak.

Dari hasil uji coba yang dilakukan oleh user, didapatkan hasil bahwa terdapat 14 berita yang kategorinya dinyatakan relevan antara pendapat user atau tester dengan hasil dari sistem klasifikasi yang dapat dilihat pada tabel 2. Pada pengujian yang dilakukan dengan menggunakan 18 berita uji, dihasilkan keakuratan sebesar $77 \%$, dengan error rate sebesar $23 \%$.

Akurasi $=\frac{14}{18} \times 100 \%=77 \%$

\section{KESIMPULAN DAN SARAN}

Dari hasil penelitian yang telah dilakukan, dapat ditarik kesimpulan sebagai berikut :

Aplikasi klasifikasi berita olahraga menggunakan metode Nä̈ve Bayes dengan Enhanced Confix Stripping Stemmer mampu mengklasifikasi berita olahraga dengan keakuratan sebesar $77 \%$ dengan tingkat kesalahan mencapai $23 \%$.

Saran yang dapat peneliti sampaikan :

1. Diharapkan menggunakan metode feature selection agar token yang dihasilkan lebih teringkas.

2. Diharapkan menggunakan metode klasifikasi lainnya seperti Support Vector Machine, untuk mengetahui perbandingan keakuratannya.

3. Jumlah dokumen latih dan uji ditambah dan skenario pemilihan dokumen diperbanyak untuk melihat sejauh mana tingkat akurasi dari motode yang digunakan.

\section{DAFTAR PUSTAKA}

THOMAS M. CONNOLY., CAROLYN E. BEGG. 2015. Database System : A Practical Approach to Design, Implementation, and Management.

JIAWEI HAN., MICHELINE KAMBER. 2000. Data Mining : Concepts and Techniques.

TRIAWATI., CHANDRA. 2009. Metode Pembobotan Statistical Concept Based untuk Klastering dan Kategorisasi Dokumen 
Berbahasa Indonesia. Institut Teknologi Telkom, Bandung.

I PUTU ADI DKK. 2008. Penggunaan Algoritma Semut Dan Confix Stripping Stemmer Untuk Klasifikasi Dokumen Berita Berbahasa Indonesia.

FRIEDMAN ET AL. 1997. Bayesian Network Classifiers., Volume 29, Issue 2-3, pp 131163.

ABRAHAM, R.., SIMHA, J.B. \& IYENGAR, S. 2009. Effective Discretization and Hybrid Feature Selection Using Nä̈ve Bayesian Classifier For Medical Data Mining. International Journal of Computational Intelligence Research 4

ZGAN \& GAO. 2011. An Improvement to Naive Bayes for Text Classification.

MUKHERJEE \& SHARMAA. 2012. Intrusion Detection using Naive Bayes Classifier with Feature Reduction. A Department of Computer Science, Banasthali University, Jaipur, Rajasthan, 304022, India.

EAMONN KEOGH, Nä̈ve Bayes Classifier.

BAGUS SETYA RINTYARNA. 2016. Pengaruh Seleksi Fitur Pada Skema Klasifikasi Naive Bayes Berbasis Gaussian dan Kernel Density. Volume 01, Nomor 01.

DWI WIDIASTUTI. 2012. Analisa Perbandingan Algoritma Svm, Naive Bayes, Dan Decision Tree Dalam Mengklasifikasikan Serangan (Attacks) Pada Sistem Pendeteksi Intrusi. Universitas Gunadarma.

DENNY NATHANIEL CHANDRA., GEDE INDRAWAN., I NYOMAN SUKAJAYA. 2016. Klasifikasi Berita Lokal Radar Malang Menggunakan Metode Nä̈ve Bayes Dengan Fitur N-Gram. Vol. 10, No. 1.

NOVIA BUSIARLI., LIAN AGA ADITYA., ALBERTUS YOKI ANDIKA. 2016. Penerapan Algoritma Nä̈ve Bayes \& Natural Language Processing Untuk Mengklasifikasi Jenis Berita Pada Arsip Pemberitaan.

DIO ARIADI., KARTIKA FITHRIASARI. 2015. Klasifikasi Berita Indonesia Menggunakan Metode Nä̈ve Bayesian Classification dan Support Vector Machine dengan Confix Stripping Stemmer. Vol. 4. No.2.

ACMAD NURHADI. 2016. Implementasi Algoritma Naïve Bayes Classifier Berbasis Particle Swarm Optimization (PSO) Untuk Klasifikasi Konten Berita Digital Bahasa Indonesia. Volume 8 No 3.

YOSEPH SAMUEL., ROSA DELIMA., ANTONIUS RACHMAT. 2015. Implementasi Metode K-Nearest Neighbor dengan Decision Rule untuk Klasifikasi Subtopik Berita.

RONEN FELDMAN., JAMES SANGER. 2007. The Text Mining Handbook : Advanced
Approaches in Analyzing Unstructured Data.

ELLY MUNINGSIH. 2016. Klasifikasi Konten Berita Digital Bahasa Indonesia Menggunakan Support Vector Machines (SVM) Berbasis Particle Swarm Optimization (PSO). AMIK BSI Yogyakarta.

MUHAMAD RACHLI. 2007. Email Filtering Menggunakan Nä̈ve Bayesian. Institut Teknologi Bandung.

AGUS SETIAWAN., INDAH FITRI ASTUTI., AWANG HARSA KRIDALAKSANA. 2015. Klasifikasi dan Pencarian Buku Referensi Akademik Menggunakan Metode Naïve Bayes Classifier (NBC). Vol. 10 No. 1 .

ANDITA DWIYOGA TAHITOE., DIANA PURWITASARI. 2010. Implementasi Modifikasi Enhanced Confix Stripping Stemmer Untuk Bahasa Indonesia Dengan Metode Corpus Based Stemming.

DIAH PUDI LANGGENI1., ZK. ABDURAHMAN BAIZAL., YANUAR FIRDAUS A.W. 2010. Clustering Artikel Berita Berbahasa Indonesia Menggunakan Unsupervised Feature Selection.

MCCALLUM., NIGAM. 1998. A Comparison of Event Models for Naive Bayes Text Classification.

MUHAMAD, HUSIN et al. Optimasi Naïve Bayes Classifier Dengan Menggunakan Particle Swarm Optimization Pada Data Iris. Jurnal Teknologi Informasi dan Ilmu Komputer, [S.1.], v. 4, n. 3, p. 180-184, sep. 2017. ISSN 2528-6579. 